\title{
The Effect of Mass Ratio of Ferrocene to Camphor as Carbon Source and Reaction Time on the Growth of Carbon Nanotubes
}

\author{
Praswasti Pembangun Dyah Kencana Wulan ${ }^{1 *}$, Nur Safitrah Setiawati ${ }^{2}$ \\ ${ }^{1}$ Department of Chemical Engineering, Faculty of Engineering, Universitas Indonesia, Kampus UI-Depok, Jawa Barat \\ 16424, Indonesia \\ ${ }^{2}$ Sustainable Energy Research Group, Department of Chemical Engineering, Faculty of Engineering, Universitas Indonesia, \\ Kampus UI-Depok, Jawa Barat 16424, Indonesia
}

\begin{abstract}
This research aims to identify the best reaction time and mass ratio of camphor to ferrocene as carbon source in the growth of carbon nanotube (CNT). Ferrocene is used as carbon source and catalyst with stainless steel (SS)-316 type gauze as substrate.Camphor as alternative carbon source is intended to improve the CNT synthesis results. This research has shown that benzene, toluene, and xylene dominate camphor decomposition, so the addition will produce good quality CNT and increase the yield. The variation of mass ratio of camphor to ferrocene was 3:1, 2:1, 1:2, 1:3 and the variation of reaction time was 10,20,30,40, and $60 \mathrm{~min}$. The synthesis results of the CNT were characterized using FESEM-EDS while the ferrocene and camphor decomposition gas was analyzed by GC-FID. The best quality of CNT was obtained at 1:2 mass ratio with yield $37 \%$, carbon percentage of $76.98 \%$ and diameter of $77-151 \mathrm{~nm}$. Increasing the reaction time from 10 to 20 minutes will increase the yield and quality of CNTs. The yield and quality of the CNT decreased after a reaction time of 30 minutes due to the deactivation of the catalyst and the closure of the active sites by nucleation and carbon growth.
\end{abstract}

\section{Introduction}

Since their first discovery, the synthesis of carbon nanotubes (CNTs) has attracted much attention due to their unique characteristics and potential applications in many fields. Various methods of producing CNTs have been reported, including electric arc-discharge, laser ablation, and chemical vapor deposition (CVD) In order for CNTs to be commercially utilized, the production of CNTs has to be achieved at high yield, low cost, high purity and with much greater control over the key characteristics such as length and diameter.

The key of costs control in CNT fabrication process include: raw materials (carbon source), catalysts, and energy requirements [1]. Chemical Vapor Deposition (CVD) is the most economical method for CNT fabrication. Low-cost catalysts are also needed to reduce the energy requirements of CNT forming processes, one of which is ferrocene [2,3]. Ferrocene can act as iron precursor that economical and not carcinogenic. At temperatures higher than $500^{\circ} \mathrm{C}$, the ferrocene decomposes spontaneously throughout with the chemical reaction $\mathrm{Fe}^{-}+\left(\mathrm{C}_{5} \mathrm{H}_{5}\right) \rightarrow 2 \mathrm{Fe}+\mathrm{H}_{2}+\mathrm{CH}_{4}$ $+\mathrm{C}_{5} \mathrm{H}_{6}+\ldots$ into reactive hydrocarbons and iron clusters play role as nuclei of the catalyst [4]. In this case, ferrocene with its carbon atoms work not only as catalyst but also can act as a carbon source. In addition, as comparisons, camphor would be added along with ferrocene as alternative carbon source since camphor obtained from Cinnamomum camphora tree so that it is renewable, economical and relatively safe to use [5]. On the other hand, research conducted by Kumar and Ando in 2007 showed that camphor $\left(\mathrm{C}_{6} \mathrm{H}_{10} \mathrm{O}\right)$ able to produce MWNT at temperature of $650^{\circ} \mathrm{C}[6]$. Camphor is believed to be capable of producing CNTs with high efficiency due to the carbon ring contained in camphor (contained in the form of pentagonal and hexagonal). The paper investigate the effects of mass ratio of camphor to ferrocene as carbon source and reaction time on the growth of carbon nanotube

\section{Methodology/Experimental}

This study consists of two parts, first is to find the optimum of mass ratio of camphor to ferrocene as

\footnotetext{
Corresponding author: wulan@che.ui.ac.id
} 
carbon source and the second is to identify the effect of reaction time in the growth of carbon nanotube (CNT). The variation of mass ratio of camphor to ferrocene was $3: 1,2: 1,1: 2,1: 3$ and the variation of reaction time was 10,20,30,40, and $60 \mathrm{~min}$. Stainless steel (SS)-316 type gauze is used as substrate. Stainless steel is a potential substrate for CNT fabrication on a commercial scale because it is affordable and easy to obtain. Stainless steel contains Fe above $60 \%$ and Ni so it can act as both the substrate and catalyst [7]. In this experiment, a - vertical tubular reactor made of stainless steel type 316 (SS 316) with one furnace was prepared as shown in Fig 1. Preparation of SS 316 catalytic substrate by oxidative heat treatment method also be done to increase the growth of CNT. Substrate firstly being soaked in hydrocolic acid ( $\mathrm{HCl}) 37 \%$ to destruct the chromium layer for about 10 minutes, then treated with oxidative heat treatment $(\mathrm{OHT})$ at $850^{\circ} \mathrm{C}$ for 30 minutes. After the OHT process, all materials are ready to be used in CNT synthesis process. The substrates were placed on each tray above the carbon source bucket. The carbon sources were placed in the carbon source bucket and the carrier gas would flow from above the bucket to the top of reactor. For the mass ratio variation, the ratio calculation isnt calculated by comparing the total weight, but only carbon molecular weight that contained in each of the carbon source. The amount of each carbon source is shown in Table 1.

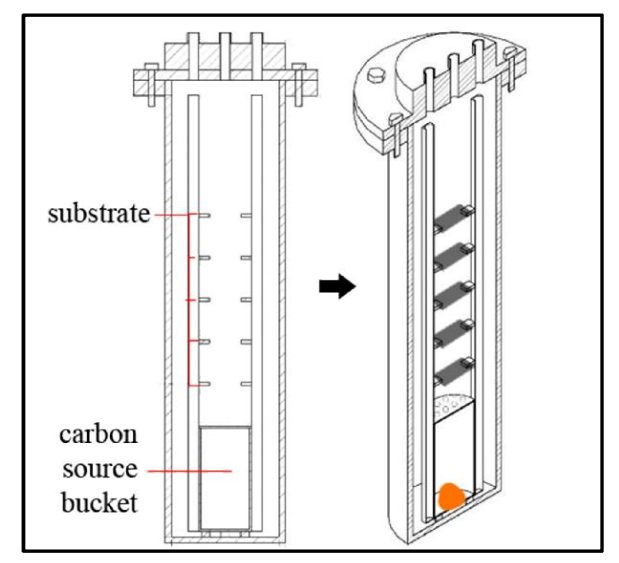

Fig 1. CNT Synthesis Reactor

Table 2. Calculation of Carbon Source for Synthesis of CNT

\begin{tabular}{cccc}
\hline $\begin{array}{c}\text { Mass Ratio } \\
\text { (Ferrocene } \\
\text { to Camphor) }\end{array}$ & $\begin{array}{c}\text { Ferrocene } \\
\text { Mass } \\
\text { (gram) }\end{array}$ & $\begin{array}{c}\text { Camphor } \\
\text { Mass } \\
\text { (gram) }\end{array}$ & $\begin{array}{c}\text { Total Mass of } \\
\text { Carbon } \\
\text { Source (gram) }\end{array}$ \\
\hline $\begin{array}{c}\mathbf{1 0 0} \% \\
\text { ferrocene }\end{array}$ & 12 & - & 12.00 \\
$\mathbf{3 : 1}$ & 9.00 & 2.45 & 11.45 \\
$\mathbf{2 : 1}$ & 8.00 & 3.27 & 11.27 \\
$\mathbf{1 : 1}$ & 6.00 & 4.9 & 10.90 \\
$\mathbf{1 : 2}$ & 4.00 & 6.54 & 10.53 \\
$\mathbf{1 : 3}$ & 3.00 & 7.35 & 10.35 \\
\hline
\end{tabular}

Once all the equipment was connected, all the connection were checked to make sure that there were no gas leaks was used to provide an inert atmosphere and to purge unknown gases from the air proof system as well as a carrier gas with volumetric flow $150 \mathrm{sccm}$. After all the part of experiment's equipment had been checked, the furnace was turned on and set to the desired reaction temperature, $850^{\circ} \mathrm{C}$. For the first variation, 20 minutes was used as reaction time. When furnace reached temperature $175^{\circ} \mathrm{C}, 500^{\circ} \mathrm{C}$, and $850^{\circ} \mathrm{C}$, the gas output was analyzed by Gas ChromatographyFlame Ionization Detectors (GC-FID) to understand the sublimation and decomposition of camphor-ferrocene mixture. The carbon nanotube product was collected from the substrate and also scraped off from the inside of the reactor. The product was analysed with Field Emission Scanning Electron Microscope (FE-SEM) and Energy Dispersive X-Ray Spectroscopy (EDX).

\section{Result and Discussion}

\subsection{Variation of Mass Ratio of Ferrocene to Camphor}

For mass ratio ferrocene to camphor 1:1, analysis of gas output using Gas Chromatography-Flame Ionization Detectors (GC-FID) was done. It took 51 minutes for the furnace to reach the desired reaction temperature, 12 minutes to reach temperature $175^{\circ} \mathrm{C}$, more 12 minutes to reach, and more 17 minutes to reach $850^{\circ} \mathrm{C}$. From the gas analysis result, we can contain the mol percentage composition of the gas as shown in Table 3.

Table 3. GC-FID Composition Calculation Result of Sublimation and Decomposition of Camphor and Ferrocene

\begin{tabular}{cccc}
\hline & $\mathbf{1 7 5}^{\circ} \mathbf{C}$ & $\mathbf{5 0 0}^{\circ} \mathbf{C}$ & $\mathbf{8 5 0}^{\circ} \mathbf{C}$ \\
\hline Methane & $0.68 \%$ & $0.43 \%$ & $1.47 \%$ \\
Hydrogen & $73.70 \%$ & $17.96 \%$ & $19.60 \%$ \\
Benzene & $4.38 \%$ & $62.34 \%$ & $55.06 \%$ \\
Toluene & $6.45 \%$ & $6.10 \%$ & $8.80 \%$ \\
Xylene & $14.79 \%$ & $13.18 \%$ & $15.07 \%$ \\
\hline
\end{tabular}

Ferrocene and camphor both would be sublimated at temperature above $175^{\circ} \mathrm{C}$. For sublimation stage, ferrocene would be deposited first on substrate's surface caused by its density that higher than camphor's. (ferrocene $=1,107 \quad \mathrm{~g} / \mathrm{cm}^{3}$ and camphor $\left.=0,992 \mathrm{~g} / \mathrm{cm}^{3}\right)$. The result shown that camphor would be decomposited to benzene, toluene, and xylene. The amount of xylene also increase as the temperatute increase. 
Table 4. Result of Synthesis of CNT with Variation of Mass Ratio

\begin{tabular}{ccc}
\hline Mass Ratio* & CNT (gram) & Yield CNT \\
\hline $\begin{array}{c}\text { Ferrocene } \\
\text { 100\% }\end{array}$ & 5.43 & $45 \%$ \\
$3: 1$ & 1.86 & $16 \%$ \\
$2: 1$ & 2.63 & $23 \%$ \\
$1: 1$ & 5.39 & $49 \%$ \\
$1: 2$ & 3.87 & $37 \%$ \\
\hline
\end{tabular}

The effect of the camphor addition to ferrocene as carbon source to the product yield was studied and the results are shown in Table 4 and Fig. 2. Because of the consistency of the carbon molecular weight in each carbon source and ferrocene have bigger total molecular weight than camphor, the decrease of mass ratio of ferrocene to camphor would caused decline of the total mass of carbon source. But, it is found that the yield were still increasing until 1:2 mass ratio, as shown as Fig.2. From previous research, it was concluded that catalyst concentration was limited by the low solubility of ferrocene [8] in the investigated hydrocarbon (ethanol, 1-propanol, cyclopentane, nhexane, cyclo hexane), but benzene, toluene, xylene, and 1,2-dichlorobenzene have much higher solubility of ferrocene [9]. As shown in the table 3, benzene dominated the carbon source for the CNT growth.

Tabel 5. EDX Results for Mass Ratio Variation

\begin{tabular}{cccc}
\hline Mass Ratio & $\begin{array}{c}\text { C (\% } \\
\text { weight) }\end{array}$ & $\begin{array}{c}\text { Fe (\% } \\
\text { weight) }\end{array}$ & $\begin{array}{c}\text { O (\%) } \\
\text { weight) }\end{array}$ \\
\hline Ferrocene 100\% & 79.41 & 15.11 & 5.48 \\
$\mathbf{3 : 1}$ & 59.68 & 31.68 & 4.64 \\
$\mathbf{2 : 1}$ & 71.87 & 22.33 & 5.21 \\
$\mathbf{1 : 2}$ & 76.98 & 15.79 & 4.60 \\
$\mathbf{1 : 3}$ & 79.82 & 11.73 & 6.50 \\
Camphor 100\% [10] & 82.70 & 8.90 & 8.30 \\
\hline
\end{tabular}

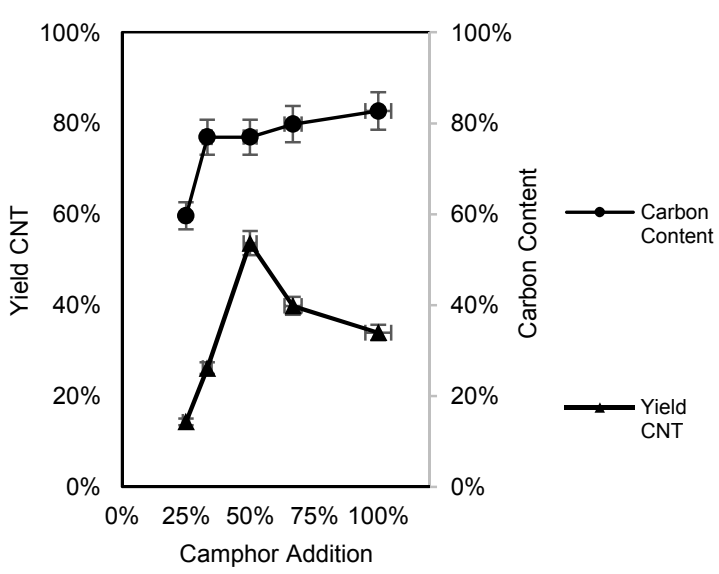

Fig 2. The Effect of Addition of Camphor to Carbon Yield, CNT Yield, and Carbon Content in CNT
As the amount of camphor increased, the content of carbon and oxygen in the mixture respectively increased as well. Thus, the mixture of iron decreased due to decomposition process of oxygen and ferrocene in the camphor into $\mathrm{Fe}+\mathrm{CH}_{4}+\mathrm{H}_{2}+\mathrm{C}_{5} \mathrm{H}_{6}$. Higher content of carbon in camphor $75 \%$ comparing with $100 \%$ ferrocene showed that, carbon resulted from camphor decomposition process (benzene,toluene, and xylene) giving more significant impact to increase CNT yield then the carbon resulted from ferrocene decomposition process (methane and cyclopentadieane)

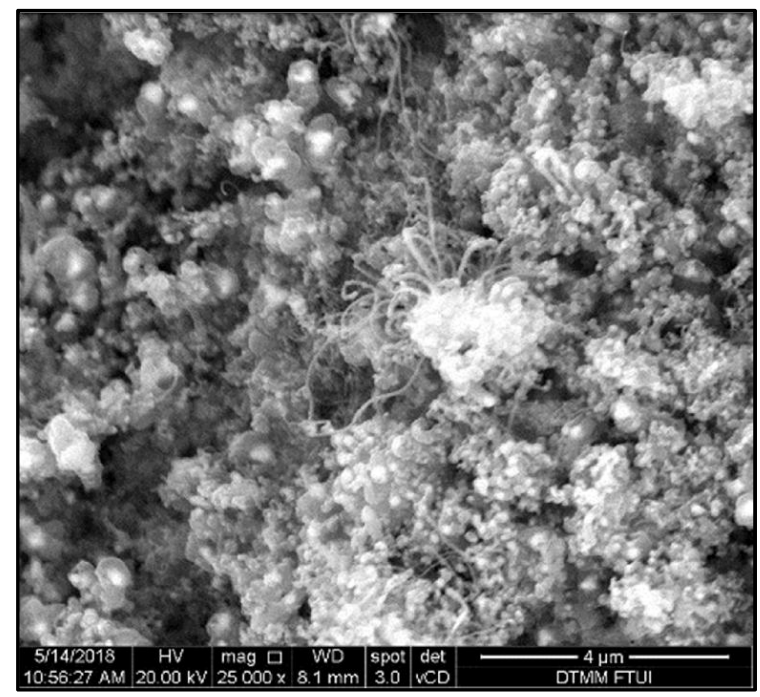

Fig 3. Morphology of Nanocarbon from 100\% Ferrocene by SEM

Fig 3. Shows the result of scanning electron microscopy of CNT growth with ferrocene as both the only carbon source and catalyst. It reveals that no clear growth of CNT formation was occurred. As seen in fig. 4 for $\mathrm{a}$ and $\mathrm{b}$ samples have formed CNT but have not showed that CNTs grow upright with extremely huge diameter and much impurities. The addition of camphor up to $50 \%$ made a clear grow of nanocarbon. The 1:1 ferrocene to camphor mass ratio produced carbon nanofilament and 1:2 ferrocene to camphor produced more tubules. From this SEM result itself the best result is generated by a ratio of $1: 2$, which later this comparison will be used to see the effect of reaction time on CNT growth. The more camphor added, the CNT growth became clearer. High amount of catalyst may formed aglomeration of catalyst particle and caused the growth of CNT with multi walltyped.

Fig.4 shows that CNT diameter that produce got smaller as the addition of camphor increase. At lower amount of ferrocene, the lower growth rate is due to the lack of sufficient Fe clusters to catalyze the growth of the aligned CNTs, whereas at high amount of ferrocene , the reduced growth rate is caused by the low catalytic activity of the larger Fe clusters since the high amount of ferrocene decompose more Fe clusters in the tubular furnace which then aggregate and grow into larger clusters with weaker catalytic effect than the smaller clusters. [11] Furthermore, a report by Kumar et al. has obtained MWNTS in very high yield and high purity 
with diameter 25-50 $\mathrm{nm}$ using camphor and ferrocene. The purity may be attributed to the extremely low intake of ferrocene $(1 \mathrm{wt} . \%)$ with camphor, which accounts for an atomic $\mathrm{Fe} / \mathrm{C}$ ratio of $0.08 \%$ in the feedstock. [12] Since the Fe clusters produced at lower concentrations are smaller than those produced at higher concentrations, the aligned CNTs catalyzed by lower ferrocene concentrations will have better crystal structures and smaller diameters than those catalyzed by higher ferrocene concentrations. [11] Therefore, lower amount of ferrocene provide better conditions for the growth of single-walled CNTs and aligned CNTs with smaller diameters

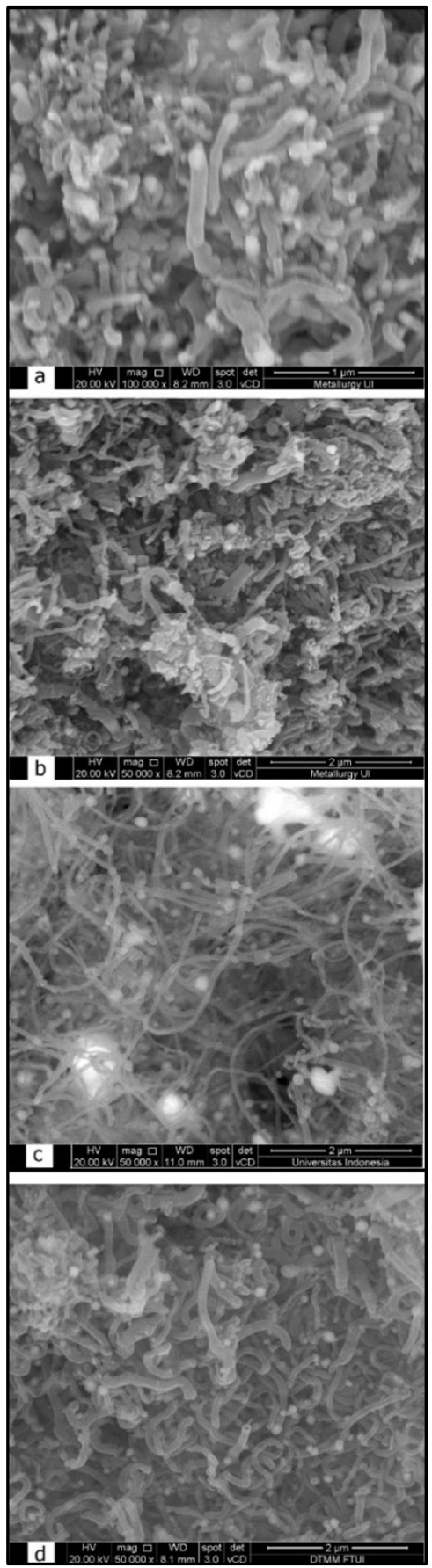

Fig 4. Morphology of CNT with mass ratio of ferrocene to camphor ; (a) $3: 1$, (b) $2: 1$, (c) $1: 1$, (d) $1: 2$
From its diameter, it concludes that CNT that formed were Multi Walled Carbon Nanotubes (MWCNT). MWCNT have diameter range about 10$240 \mathrm{~nm}$ [13]. It also seems that there were deformation in the growth of CNT that indicated the buckling growth. Along with the CNT growth process, CNT can be collided or twisted with other CNTs and/or with small clusters of catalysts. This interaction process cause bending of CNT which lead to deformations on CNT surfaces. The absence of the termination process of CNT growth causes CNT to continue look for space to grow, so that the bending section will bend permanently and form CNT with buckling growth [14].

\subsection{Effects of Reaction Time on The Growth of CNT}

To identify the effects of the reaction time to the growth of CNT, gas output from up to 20 minutes was analyzed with Gas Chromatogram as shown in the Table 6

Table 6. GC-FID Composition Calculation Result of Decomposition of Camphor and Ferrocene at $850^{\circ} \mathrm{C}$

\begin{tabular}{ccccc}
\hline & $\mathbf{2 0} \mathbf{~ m i n}$ & $\mathbf{3 0} \mathbf{~ m i n}$ & $\mathbf{4 0} \mathbf{~ m i n}$ & $\mathbf{6 0} \mathbf{~ m i n}$ \\
\hline Methane & $0.36 \%$ & $0.62 \%$ & $0.25 \%$ & $0.39 \%$ \\
Hydrogen & $18.82 \%$ & $10.28 \%$ & $0.17 \%$ & $0.06 \%$ \\
Benzene & $77.53 \%$ & - & - & - \\
Toluene & - & - & - & - \\
Xylene & - & - & - & - \\
\hline
\end{tabular}

Table 7. CNT Product in Reaction Time Variation

\begin{tabular}{cccc}
\hline $\begin{array}{c}\text { Reaction } \\
\text { Time }\end{array}$ & $\begin{array}{c}\text { CNT On } \\
\text { Substrate } \\
(\mathbf{g})\end{array}$ & $\begin{array}{c}\text { CNT On } \\
\text { Reaktor } \\
\text { Wall (g) }\end{array}$ & $\begin{array}{c}\text { Total } \\
\text { CNT } \\
\text { (gram) }\end{array}$ \\
\hline $10 \mathrm{~min}$ & 1.49 & 2.66 & 4.15 \\
$20 \mathrm{~min}$ & 1.50 & 2.37 & 3.87 \\
$30 \mathrm{~min}$ & 1.16 & 4.19 & 5.35 \\
$40 \mathrm{~min}$ & 1.22 & 4.60 & 5.82 \\
$60 \mathrm{~min}$ & 1.16 & 3.56 & 4.72 \\
\hline
\end{tabular}

Table 8. EDX Results for Mass Ratio Variation

\begin{tabular}{ccccc}
\hline $\begin{array}{c}\text { Reaction } \\
\text { Time }\end{array}$ & $\begin{array}{c}\text { C (\% } \\
\text { weight) }\end{array}$ & $\begin{array}{c}\text { O (\% } \\
\text { weight) }\end{array}$ & $\begin{array}{c}\text { Cr (\% } \\
\text { weight) }\end{array}$ & $\begin{array}{c}\text { Fe (\% } \\
\text { weight) }\end{array}$ \\
\hline $10 \mathrm{~min}$ & 80.20 & 5.20 & 1.00 & 13.60 \\
$20 \mathrm{~min}$ & 84.84 & 6.48 & 0.67 & 8.01 \\
$30 \mathrm{~min}$ & 75.80 & 8.00 & 0.90 & 15.30 \\
$40 \mathrm{~min}$ & 80.40 & 5.40 & 1.20 & 13.00 \\
$60 \mathrm{~min}$ & 79.40 & 5.80 & 1.80 & 13.00 \\
\hline
\end{tabular}


From Table 7 we can conclude that CNT growth still occured up to 20 minutes on the substrate. Table 6 also shown that in min 20 , there was only few carbon content in the gas output in form of benzene that came from the decomposition process of camphor. In min.30, the carbon content decreases while the $\mathrm{H}_{2}$ gas increases, then in $\min 40$, the output gas contain of $96 \%$ carrier gas, no hidrocarbon and $\mathrm{H}_{2}$ found. This indicates that decomposition of both ferrocene and camphor have finished, therefore the amount of CNT was no longer increase. Since high content of $\mathrm{H}_{2}$ found at minute 30th in gas chromatography result and the result of EDX that shown in Table 8 shows the highest Fe amount showed at the same time reaction, it could be concluded that the hydrogen atoms have a role to maintain the activity of the catalyst [15]. From 10 to 30 min, it appears that both amount of oxygen and carbon increased and started decreases at the $40 \mathrm{~min}$. This increased of carbon could be attributed to the role of oxygen that oxidize the amorphous carbon. [12]

Fig 5. shows that from $10 \mathrm{~min} \mathrm{CNF}$ has already formed with diameter $70-97 \mathrm{~nm}$. At $20 \mathrm{~min}$, the nanocarbon became more tubular and CNT has formed with thicker diameter (89-114). In accordance with the results of gas chromatography itself it appears that after 20 minutes, the content of the gas output already contains very little carbon that only comes from benzene so that in $30 \mathrm{~min}$, more agglomeration formation seen in the Fig 5. and deposit of amorphous carbon than the addition of CNT product. This amorphous carbon deposit also attributed to the thickness of MWCNT wall.

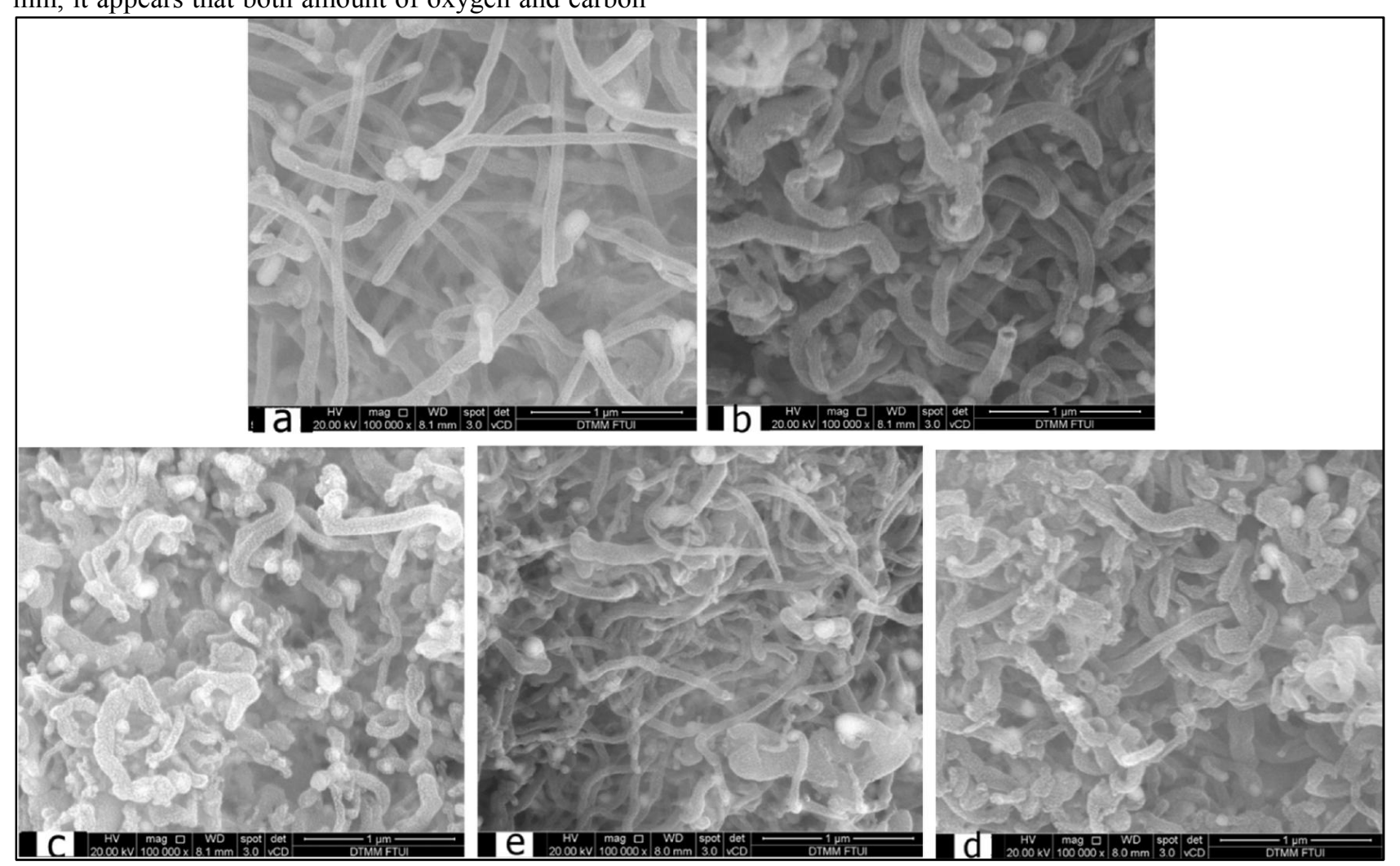

Fig 5. Morphology of CNT with reaction time ; (a) $10 \mathrm{~min}$, (b) $20 \mathrm{~min}$, (c) $30 \mathrm{~min}$, (d) $40 \mathrm{~min}$, (e) $60 \mathrm{~min}$

The XRD result shows that CNTs are formed on each sample of variation. CNT was confirmed by XRD patterns with peak $26^{\circ}, 43^{\circ}$, and $54.5^{\circ}$. In addition, there are several other peaks indicating impurities. The impurities include some carbon amorphous (peaks at 45 and $58.5^{\circ}$ ), $\mathrm{Fe}_{3} \mathrm{C}$ (peaks at 38 and $41^{\circ}$ ), $\mathrm{Fe}_{2} \mathrm{O}_{3}$ (peaks at 34.5 and $53^{\circ}$ ) [16] and $\mathrm{Fe}_{3} \mathrm{O}_{4}$ (peak at $30^{\circ}$, $35^{\circ}$, and $63^{\circ}, 45^{\circ}$ ) [17]. Fig 6. shows that in 20 minutes CNT growth dominated with reaction time up to 20 minutes. $\mathrm{Fe}_{3} \mathrm{O}_{4}$ was formed through the interaction between $\mathrm{Fe}$ and oxygen in very low selectivities. Fe was partly derived from ferrocene decomposition and others from the SS-316 dissociation wes reacted oxygen from camphor decomposition. $\mathrm{Fe}_{3} \mathrm{C}$ was formed by the interaction between $\mathrm{Fe}$ metals and carbon gases from the carbon source's decomposition process. The presence of $\mathrm{Fe}_{3} \mathrm{C}$ indicates that there were several catalyst particles entering CNT's body. Amorphous carbon was formed due to sooting in the catalyst caused by the CNT growth termination process or saturation of the catalyst [18] 


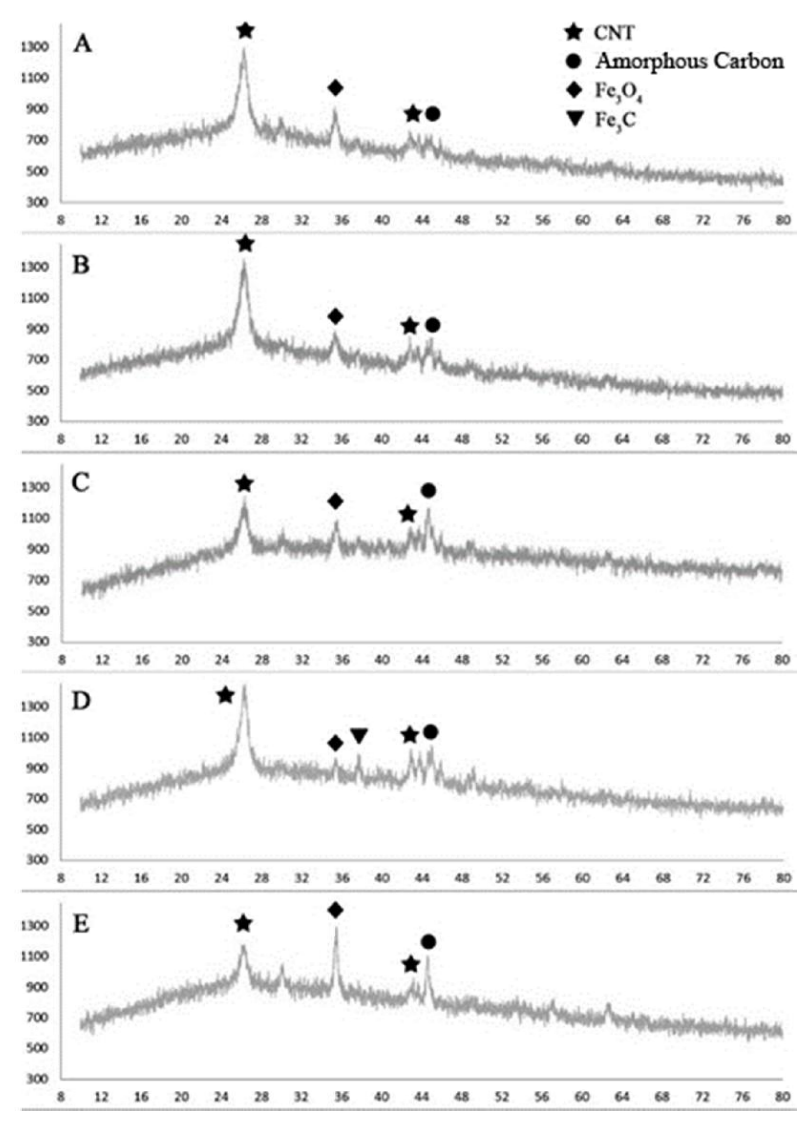

Fig 6. XRD patterns of CNT with reaction time ; (a) $10 \mathrm{~min}$, (b) $20 \mathrm{~min}$, (c) $30 \mathrm{~min}$, (d) $40 \mathrm{~min}$, (e) $60 \mathrm{~min}$

\section{Conclusion}

In this paper, we synthesize CNT with ferrocene as carbon source and catalyst, added with camphor as alternative carbon source that was intended to improve the quality of CNT products. The synthesis process has been investigated with regard to the two different parameters: the best reaction time and mass ratio of camphor to ferrocene as carbon source. It was found that an increase of mass ratio of camphor to ferrocene would reduce the diameter of the tube with better quality. In 20 minute CNT had formed and the increase of reaction time will increase the diameter of CNTs. In min 30 all carbon source decomposition had finished and more agglomeration and deposit of amorphous carbon formed than the addition of CNT product, that contributed to the thickening of MWCNT wall,too. The yield of CNT on substrate and quality of the CNT decreased after reaction time of 30 minutes might happened due to the deactivation of the catalyst and the closure of the active sites by nucleation and carbon growth. The best quality of CNT was obtained at $1: 2$ in mass ratio in 20 min reaction with yield $37 \%$, carbon percentage of $76.98 \%$ and diameter of $77-151$ $\mathrm{nm}$.

The authors acknowledge the financial support received from Directorate of Research and Community Service Universitas Indonesia under PITTA Grant 2018 contract number: 2506/UN2.R3.1/HKP.05.00/2018. We are thankful, to Laboratory of Chemical and Resource Product Engineering (RPKA) Department of Chemical Engineering and Center of Material Processing and Failure Analysis Laboratorium (CMPFA) Department of Metalurgy and Material Universitas Indonesia, and also Center of Polimer Techology - BPPT for the instruments characterization.

\section{References}

1. C. Zhuo, Wang, Xin, W.N. Yiannis, A. Levendis, J. Appl. Surf. Sci., 313, 227-236 (2014)

2. T.M. Keller, M. Laskoski, S.B. Qadri, J. Phys. Chem. C 111, 6, 2514-2519 (2007)

3. M.C.M. Zambri, N.M. Mohamed, C.F. Kait, J. Appl. Sci. 11 (8), 1321-1325 (2011)

4. A. Leonhardt, S. Hampel, C. Müller, I. Mönch, R. Koseva, M. Ritschel, D. Elefant, K. Biedermann, B. Büchner, Chemical vapor deposition 12, 380 (2006)

5. P.P.D.K. Wulan, T.P.J. Silaen, AIP Conference Proceedings 1840, 080003 (2017)

6. M. Kumar, Y. Ando, J. Phys. Conf. Series 61, 643646 (2006)

7. M Cai. F.S., J. Wang, Z.H. Yuan, X.L. Du. J., Optoelectron Adv M 14, 267-271 (2012)

8. Z.E Horvath, K. Kertész, L. Petho, A.A. Koós, L. Tapasztó, Z. Vértesy, Z. Osváth, Al. Darabont, P. Nemes-Incze, Zs. Sárkö zi, L.P. Biró, Curr. Appl. Phys. 6, 135-140 (2006)

9. U. Weissker, S. Hampel, A. Leonhardt, B. Büchner, J. Materials 3, 4387-4427 (2010)

10.P.P.D.K. Wulan, D. Angeline, AIP Conference Proceedings 1904, 020080 (2017)

11. B.Xiaodong, L. Dan, W.Ye, Tsinghua Science and Technology 10.6, 729-735 (2005)

12. M. ,Kumar, Y. Ando, J. Diamond Rela. M. 12, 9981002 (2003)

13. K.A. Shah, B.A. Tali, Materials Science in Semiconductor Processing, 41, 67-82 (2016)

14. Q. Zhang, J.Q. Huang, M.Q. Zhao, W.Z. Qian, F. Wei, ChemSusChem 4,864 - 889 (2011)

15. N. Mishra, M. Sharon, J. Anal. Appl. Pyro. 94, 9198 (2012)

16. Mopoung, S. Int. J. Phys. Sci 7,1789 - 1792 (2011)

17. Yusmaniar, W. A. Adi, Y. Taryana, R. Muzaki, IOP Conf. Ser.: Mater. Sci. Eng., 196012033 (2017)

18. P.P.D.K. Wulan, S.B. Wijardono, Int. J. Adv. Sci. Eng. Inf. Tech., 7, 2088-5334 (2017) 